\title{
Husband's participation in birth preparedness and complication readiness
}

\author{
Mahendra G. ${ }^{1}$, Afra Farheen M.V. ${ }^{2}$, Vijayalakshmi. S. ${ }^{3}$ \\ ${ }^{1}$ Dr. Mahendra. G, Associate Professor, ${ }^{2}$ Dr. Afra Farheen M.V., Junior Resident, ${ }^{3}$ Prof. Dr. Vijayalakshmi. S. Professor and \\ Head of the Department; all authors are affiliated with Department of Obstetrics and Gynecology, Adichuchangiri Institute of \\ Medical Sciences, Nagamangal Taluk, Mandya District, Karnataka, India.
}

Corresponding Author: Dr. Afra Farheen M.V, Junior Resident, Department of Obstetrics and Gynecology, Adichuchangiri Institute of Medical Sciences, Nagamangal Taluk, Mandya District, Karnataka, India. E-mail: afrafarheen786@gmail.com

\begin{abstract}
Introduction: Pregnancy and childbirth continue to be viewed as solely a woman's issue. Finding a male companion at antenatal care is rare. Husbands in patriarchal societies of developing countries are often identified as decision makers in all aspects of day-to-day life. Thus Husband's participation promotes active preparation and assists in decision-making in birth preparedness and in case of complications. Aim: The main objective of this study was to assess the determinant factors of male involvement in birth preparedness and complication readiness. Materials and Methods: A cross-sectional survey was conducted among 100 married Couples from June 2018 to October 2018 in tertiary care hospital, Adichunchangiri Institute of Medical Sciences, B.G Nagara, Karnataka. Data collected Using pre-structured questionnaire, Odds Ratio and 95\% confidence interval. Results: A total of 100 husbands participated in the study with $95 \%$ response rate. About $70 \%$ of the husbands had participated in birth preparedness and complication readiness. The study revealed that husbands were more likely to participate in birth preparedness if they had better knowledge in postnatal danger signs and a better knowledge on birth preparedness. Conclusion: Educated and Young aged Husbands with higher income and formal employment showed greater involvement in birth preparedness and complication readiness. Hence these factors should be emphatically considered during maternal health program development. Male awareness in postnatal danger signs and birth preparedness should be increased by local and other concerned bodies.
\end{abstract}

Key Words: Male involvement, Birth preparedness and complication readiness, Danger Signs

\section{Introduction}

Globally, more than half a million women still die annually as a result of complications of pregnancy and childbirth [1]. In 1997, the United Nations Population Fund (UNFPA) described an agenda for the International Conference on Population and Development, Cairo and Fourth World Conference on Women, Beijing, in which men would play a proactive role in the empowerment of women [2]. Men in patriarchal societies of developing countries are often identified as decision makers in all aspects of day-to-day life; pregnancy and childbirth are often regarded as women's exclusive concerns.

A male companion at antenatal care is rare and in many communities, it is unthinkable to find male companions accompanying a woman to the labour room during delivery $[3,4]$. Male involvement in reproductive health has been promoted as a promising new strategy for

Manuscript received: $10^{\text {th }}$ December 2018

Reviewed: $20^{\text {th }}$ December 2018

Author Corrected: $26^{\text {th }}$ December 2018

Accepted for Publication: 31 $1^{\text {st }}$ December 2018

Obsgyne Review: Journal of Obstetrics and Gynecology improving maternal and child health [3,4]. Strategies for involving men in maternal health services should aim at raising their awareness about emergency obstetric conditions, and engaging them in birth plans and complication readiness [5]. Most of the causes of maternal morbidity and mortality are preventable and attributed to the three delays; delay in recognizing problem and to seek care, delay to reach place of care, and delay to receive appropriate care $[3,4]$.

Birth Preparedness and Complication Readiness strategy encourage women to be informed of danger signs of obstetric complications and emergencies, Choose a preferred birth place and attendant at birth, make advance arrangement with the attendant at birth, arrange for transport to skilled care site in case of emergency, saving or arranging alternative funds for costs of skilled and emergency care, and finding a companion to be with the woman at birth or to accompany her to emergency care $[6,7]$. This study was conducted to assess the determinant

Available online at: www.medresearch.in $95 \mathrm{IP}$ a g e 
factors of male involvement male involvement in Birth preparedness and complication readiness strategy as an important support structures to help reduce delays in accessing maternal health care especially during emergencies; to reduce maternal and neonatal mortality.

\section{Methods and Materials}

\section{Study Area and Period}

Study type-cross-sectional study

Sample Size- 100 married Couples

Study period- from June 2018 to October 2018

Study Area- Tertiary care hospital, Adichunchangiri Institute of Medical Sciences, B.G Nagara, Nagamangala Taluk, Mandya Distract, Karnataka

Study Design and Source Population- A community based cross-sectional study was conducted among married couples in B.G Nagara.

\section{Inclusion criteria}

- Married male of a household head

- His willingness to participate in the study.

\section{Original Research Article}

\section{Exclusion criteria}

- Husbands who were not present with their wives during pregnancy and birth of the child.

- Those who were critically ill.

Sample Size Determination and Sample ProcedureThe sample of 100 husbands was determined using single population proportion formula with 95\% level of confidence, $5 \%$ margin of error and $70 \%$ of husbands estimated to participate in birth preparedness.

Data Collection and Procedures- Data was collected using pre-structured questionnaire. The questionnaire was designed in English and was translated to Kannada version for better understanding by interviewees during the interview time.

Data Processing and Analysis- Data were coded, entered and cleaned. Data analysis was carried out using SPSS version 20 software package. Simple descriptive statistics such as frequencies, means, and standard deviations were done as appropriate and the associated factor between the different variables in relation to the outcome variable was measured by odds ratio with $95 \%$ confidence interval.

\section{Results}

Socio-demographic characteristics of the 100 married men sampled for the study, the socio-demographic characteristics of study participants are shown in Table 1 .

Table-1: Socio-demographic characteristics of respondents $(n=100)$.

\begin{tabular}{|c|c|}
\hline Characteristic & Frequency No. (\%) \\
\hline Age & \\
\hline $20-25$ & $6(6)$ \\
$26-30$ & $50(50)$ \\
$31-35$ & $26(26)$ \\
$36-40$ & $14(14)$ \\
$41-45$ & $4(4)$ \\
Total & $100(100)$ \\
\hline Educational status & $6(6)$ \\
\hline Non-formal & $10(10)$ \\
Primary & $38(38)$ \\
Secondary & $28(28)$ \\
Tertiary & $18(18)$ \\
Degree & $100(100)$ \\
Total & $2(2)$ \\
\hline Income & $16(16)$ \\
\hline$<4,999$ & $42(42)$ \\
$5,000-9,999$ & $32(32)$ \\
$10,000-14,999$ & $8(8)$ \\
$15,000-20,000$ & $100(100)$ \\
$>20,000$ & \\
Total & \\
\hline
\end{tabular}




\section{Original Research Article}

The age of respondents ranged from 20 to 45years. Over 50\% of the respondents were between 26 and 30 years. 50 (50\%) respondents were farmers and self-employed in business, $32(32 \%)$ were drivers and government or private employees. The remaining $18(18 \%)$ had other types of work. A total of $18(18 \%)$ respondents had Degree, $28(28 \%)$ had a tertiary education, $38(38 \%)$ had a secondary education, $10(10 \%)$ had a primary education, and $6(6 \%)$ had no formal education.

Table-2: Men's perception of high risk pregnancy and danger signs in pregnancy, B.G. Nagara, 2018.

\begin{tabular}{|l|c|c|}
\hline \multirow{2}{*}{ Variable } & \multicolumn{2}{|c|}{ Frequency (\%) n=100 } \\
\cline { 2 - 3 } & Yes & No \\
\hline Pregnancies considered as high risk & & $46(46)$ \\
\hline Pregnancy while breastfeeding & $54(54)$ & $44(44)$ \\
Too frequent pregnancies & $56(56)$ & $42(42)$ \\
Pregnancy in the young mother & $58(58)$ & $54(54)$ \\
Previous operative delivery & $46(46)$ & $46(46)$ \\
Pregnancy in the older mother & $54(54)$ & \\
\hline Danger signs in pregnancy & & $44(44)$ \\
\hline Bleeding & $56(56)$ & $70(70)$ \\
Convulsions & $30(30)$ & $52(52)$ \\
Loss of consciousness & $48(48)$ & $42(42)$ \\
Paleness & $58(58)$ & $44(44)$ \\
Swollen legs/face & $56(56)$ & $64(64)$ \\
Baby stops kicking & $36(36)$ & $48(48)$ \\
Water breaks before labour pains & $52(52)$ & $60(60)$ \\
Difficulty in breathing & $40(40)$ & $44(44)$ \\
Dizziness/Blurred vision & $56(56)$ & $44(44)$ \\
Severe Headache & $56(56)$ & \\
High Fever & & \\
\hline
\end{tabular}

Table 2 shows that $58 \%$ of men considered pregnancy in younger age as high risk pregnancy. $56 \%$ of men considered too frequent pregnancies as high risk. $54 \%$ of men viewed pregnancy while a woman is still breastfeeding and pregnancy in elderly mothers as high risk. $46 \%$ men considered previous operative delivery as high risk pregnancies.

When asked to identify situations they would consider as danger signs in pregnancy, more than half(58\%) considered paleness; (56\%) considered bleeding, swollen legs/face, severe headache \& blurring of vision, high fever; (52\%) considered Water breaks before labour pains. $48 \%$ men considered loss of consciousness, $(40 \%)$ considered difficulty in breathing. About a third considered convulsions (30\%) and cessation of fetal movement as danger signs.

Table-3: Men's birth preparedness, B.G. Nagara, 2018.

\begin{tabular}{|l|c|}
\hline What men plan for & Frequency (\%) n=100 \\
\hline Mother/Baby's Clothing & $92(92)$ \\
\hline Transportation & $82(82)$ \\
\hline Savings for Delivery & $78(78)$ \\
Savings for Emergencies & $58(58)$ \\
\hline Accompanied wives for ANC visits & $74(74)$ \\
\hline Mother's health care & $60(60)$ \\
\hline Identifies decision-making process & $40(40)$ \\
\hline in case of obstetric emergency & $40(40)$ \\
\hline Arrange Blood Donor & $36(36)$ \\
\hline
\end{tabular}

Table 3 shows that most men made plans for clothing for mother/baby (92\%) and Transportation (82\%). 78\% of men saved money for delivery out of which $58 \%$ of men also saved for emergency. $74 \%$ of men accompanied their wives for ANC visits. $60 \%$ of men planned for Mother's health care. Less than half of men arranged for donor (40\%), Decision maker during emergency (40\%). Less than a third made arrangement of Skilled Birth Attendant (36\%). 


\section{Original Research Article}

Table- 4: Factors associated with male participation in maternity care, B.G. Nagara, 2018

\begin{tabular}{|c|c|c|c|c|c|c|}
\hline \multirow[t]{2}{*}{ Characteristics } & \multicolumn{4}{|c|}{ Frequency (\%) } & \multirow[b]{2}{*}{$\begin{array}{c}\text { Crude } \\
\text { ODDS } \\
\text { Ratio } \\
\end{array}$} & \multirow[b]{2}{*}{$95 \% \mathrm{CI}$} \\
\hline & $\begin{array}{c}\text { Ever } \\
\text { participated }\end{array}$ & $\begin{array}{c}\text { Never } \\
\text { participated }\end{array}$ & Total & P -Value & & \\
\hline \multicolumn{7}{|l|}{ Age group (years) } \\
\hline $\begin{array}{l}\leq 30 \\
>30 \\
\text { Total }\end{array}$ & $\begin{array}{c}48(48) \\
26(26) \\
74\end{array}$ & $\begin{array}{c}8(8) \\
18(18) \\
26\end{array}$ & $\begin{array}{c}56 \\
44 \\
100\end{array}$ & 0.0036 & 4.153 & $1.590-10.847$ \\
\hline \multicolumn{7}{|l|}{ Educational status } \\
\hline $\begin{array}{l}\text { Non-formal } \\
\text { Formal } \\
\text { Total }\end{array}$ & $\begin{array}{c}10(10) \\
68(68) \\
78\end{array}$ & $\begin{array}{c}6(6) \\
16(16) \\
22\end{array}$ & $\begin{array}{c}16 \\
84 \\
100\end{array}$ & 0.110 & 0.392 & $0.124-1.237$ \\
\hline \multicolumn{7}{|l|}{ Income } \\
\hline $\begin{array}{l}<10,000 . \mathrm{Rs} \\
\geq 10,000 \cdot \mathrm{Rs} \\
\text { Total }\end{array}$ & $\begin{array}{c}18(18) \\
48(48) \\
66\end{array}$ & $\begin{array}{c}12(12) \\
22(22) \\
34\end{array}$ & $\begin{array}{c}30 \\
70 \\
100\end{array}$ & 0.408 & 0.687 & $0.282-1.670$ \\
\hline
\end{tabular}

Table 4 shows that men under the age of 30 years (48\%) accompanied their wives to the hospital for maternity care when compared to men aged more than 30 years $(26 \%)$. Men who had formal education $(68 \%)$ were more likely to participate when compared to those with non-formal education (10\%). Men with average Monthly income of more than 10,000 Rupees (48\%) were significantly associated with participation in birth preparedness when compared to those men earning less than 10,000 Rupees (18\%).

Reasons for low participation of husbands in maternity care- Respondents during in-depth interviewed, listed out the reasons for low participation of Husbands, which include: ignorance, poverty, restriction of men entry in the maternity health unit of hospital and labour room. Respondents also added that men don't feel welcomed in the maternity units of hospitals or clinics and especially labour wards. Even when they accompany their wives, the health workers ignore them and they will only be addressed when things go wrong, to donate blood, pay for surgery or buy drugs.

Table-5: Attitude of wives toward husband's participation in maternal care, B.G. Nagara, 2018.

\begin{tabular}{|l|c|}
\hline \multicolumn{1}{|c|}{ Statement } & Frequency (\%) n=100 \\
\hline Husband should accompany wife during ANC & 74 \\
\hline Agree & 10 \\
Undecided & 16 \\
Disagree & \\
\hline Husband should accompany wife to hospital during & 78 \\
delivery & 10 \\
\hline Agree & 12 \\
Undecided & 54 \\
Disagree & 10 \\
\hline Husband should be present in labour room & 36 \\
\hline Agree & \\
Undecided & 76 \\
Disagree & 10 \\
\hline Husband should accompany wife for postnatal care & 14 \\
\hline Agree & \\
Undecided & \\
Disagree & \\
\hline
\end{tabular}

Table 5 shows that most wives were in agreement with husbands accompanying their spouses for antenatal care (74\%), delivery $(78 \%)$ and postnatal care $(76 \%)$. However, there were $54 \%$ of women who wanted the physical presence of husbands in the labour room while $36 \%$ of women strongly opposed it. 


\section{Discussion}

\section{Original Research Article}

The Millennium Development Goals (MDG) to the United Nations 2030 Agenda for Sustainable Development, the international community has established the Sustainable Development Goals (SDGs) and set the target for countries to reduce maternal mortality ratio to less than 70 per 100,000 live births by 2030 [10]. This community-based study assessed husband participation and factors associated with husbands participation in birth preparedness at B.G. Nagara. This study examined the factors associated with male involvement in Antenatal care and birth plans. The findings highlighted the associated factors such as age, education and income. Literature shows that the couples in which male had a higher level of education were better informed and so were likely to be involved in birth plan, and were more socially or financially empowered to make the necessary decisions $[5,8,9]$.

Literature shows that $61 \%$ of pregnant women had adequate preparations for delivery, while only $4.8 \%$ had preparation for emergency complications [18]. Other study shows that $62.9 \%$ of men arranged money for delivery, $67 \%$ of men knew at least one danger sign in pregnancy, while only $6.9 \%$ knew of three or more danger signs [19]. This study revealed that the men with higher education and young aged Husbands with higher income and formal employment showed greater involvement in birth preparedness and complication readiness. Men who were knowledgeable and obtained health education were more likely to accompany their spouses for ANC visit [5,8,11]. Previous findings suggested that providing information to male partners about attending antenatal care might increase their involvement, as well as greater preparedness in case of pregnancy[11-17]. WHO recommends BPCR as one of the important interventions for increasing utilization of skilled MNH services and thus averting avoidable maternal deaths [20,21]. Globally, the involvement of husbands in BPCR appears to be context specific, with low involvement overall in some regions [22,23] and high in others, [24] and selective across components in all cases.

This study highlighted reasons for low participation of husbands in maternity care: Ignorance, poverty, restriction of men entry in the maternity health unit of hospital and labour room. Respondents also added that men don't feel welcomed in the maternity units of hospitals or clinics and especially labour wards. Even when they accompany their wives, the health workers ignore them and they will only be addressed when things go wrong, to donate blood, pay for surgery or buy drugs.

Our respondents considered in descending order the following pregnancy groups as being high risk: pregnancy in younger age as high risk pregnancy, too frequent pregnancies, pregnancy while a woman is still breastfeeding and pregnancy in elderly mothers, previous operative delivery. We found that a substantial proportion of men correctly identified vaginal bleeding, paleness, headache, dizziness and blurring of vision, convulsions as obstetric emergencies. Other conditions identified were loss of consciousness, cessation of fetal movement, preterm labour, water breaks before labour pains and difficulty in breathing. These responses are higher to those mentioned by men in Northern Nigeria. It is of immense importance for husbands to correctly identify symptoms related to obstetric complications and emergencies because they constitute serious situations for both mother and child. Failure to correctly perceive these conditions as serious by the main decision-maker and financier of obstetric care may have disastrous consequences.

\section{Husbands accompanying wives for ANC visits}

This study finding shows that $74 \%$ of males accompanied their partners for ANC visits. This finding is higher when it is compared with the study done during 2015 Mekkel Town [25] in which 60.4\% husbands participated in birth preparedness and 2010 Northern Nigeria [26] in which $32.1 \%$ husbands participated in birth preparedness.

Coming to the specific practices of husbands' in birth preparedness, in this study about $92 \%$ of them have prepared clean clothes for mother and baby before delivery, this finding is higher when it is compared with the study done during 2015 Mekkel Town [25] and 2010 Northern Nigeria [26] in which $80.10 \%$ of Ethiopians and 22.6\% of Northern Nigerian husbands prepared clean clothes for the mother and baby. Besides this about $60 \%$ husbands identified place of delivery for their wife. This finding for identifying place of delivery is also higher compared with the study in Northern Nigeria [26] 9\%.

\section{Transportation for deliver}

In this study $82 \%$ of them arranged for transportation, this finding is higher when it is compared with the study done during 2015 Mekkel Town[25] and 2010 Northern Nigeria[26] in which 65.4\% of Ethiopians and 24.2\% of Northern Nigerian husbands arranged for transportation. 


\section{Savings for delivery}

In this study $78 \%$ of them saved money for delivery out of which $58 \%$ also saved money separately for emergencies, this finding is similar when it is compared with the study done during 2015 Mekkel Town [25] where in $76.3 \%$ husbands saved money for delivery and is higher when it is compared with the study done during 2010 Northern Nigeria [26]in which only $23.1 \%$ of husbands saved money for delivery.

\section{Husbands presence in labour room}
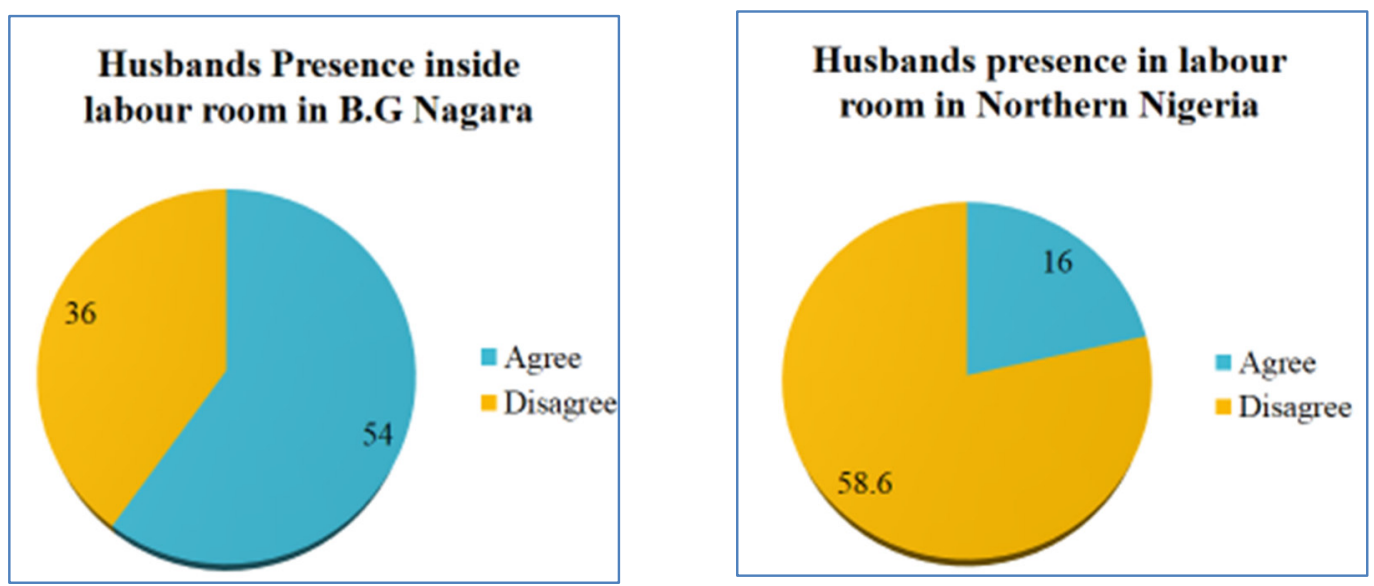

In this study around $54 \%$ of women wanted their husbands to accompany them inside the labour room to the labour cot and only $16 \%$ strongly opposed it. This finding is significantly higher when compared with the study done during 2010 Northern Nigeria [26] in which only $16 \%$ of women wanted their husbands to accompany them inside the labour room and $58.6 \%$ women strongly opposed it.

\section{Conclusion}

Educated and Young aged Husbands with higher income showed greater involvement in birth preparedness and complication readiness. Hence these factors should be emphatically considered during maternal health program development. Male awareness in postnatal danger signs and birth preparedness should be increased by local and other concerned bodies. The health office should also strengthen the health education about danger signs of pregnancy and postnatal period to increase the husbands' participation. In addition to this, counseling should be given for mothers by health care providers during antenatal, delivery and immunization period to convince their husbands about the health risks and the actual maternal health problems which in turns make husbands save money, pay in case when emergency arise, identify mode of transportation to health facility, identify blood donor ahead before emergency happen.

Antenatal care represents a window of opportunity for information; education, and communication with pregnant women so that they will make appropriate choices during pregnancy, especially when they are in danger. However, this opportunity is often missed and compounded by different associated factors. Our findings suggest that husbands' involvement is positively correlated with women's utilization of skilled services.
Addition of this study to existing knowledge: As men are the main decision makers in the patriarchal society, involvement of men in Birth preparedness and complication readiness will definitely improve the maternal and neonatal outcome by taking proper decision on time, reaching the health care center on time and making necessary arrangements prior to the date of delivery. Men should be encouraged in maternity health centers to accompany their wives during ANC visits and should be educated regarding the complications or danger signs during pregnancy; to enlighten them about complication readiness. Hence preparedness in health system, ensuring competence and motivation of workers are needed for promoting BPCR among the study population.

\section{Authors' contributions}

Dr. Mahendra. G, Dr. Afra Farheen M.V and Dr. Vijayalakshmi. S carried out the study. Dr. Afra Farheen M.V developed the theory and performed the computations. Dr. Mahendra. G verified the analytical methods. Dr. Mahendra. G encouraged Dr. Afra Farheen M.V to investigate more on reasons of husbands low participation in Maternal care and supervised the findings of this work. All authors discussed the results and contributed to the final manuscript. 


\section{Funding: Nil, Conflict of interest: Nil Permission from IRB: Yes}

\section{References}

1. WHO, UNICEF, UNFPA and World Bank. Maternal mortality in 2005. Geneva: WHO; 2007.

2. United Nations Population Fund: A new role for men: Partners for Women's Empowerment. 1997, NY: UNFPA.

3. United Nation Population Fund; SI and Burger, M.: Parentinga new approach to sexual and reproductive health. Technical paper No.3, 2000.

4. Federal Democratic Republic of Ethiopian. Ministry of Health: Antenatal Care Blended learning module for the Health extension Programmme, HEAT in Africa.

5. JHPIEGO: Maternal and Neonatal health (MNH) program, birth preparedness and complication readiness: A matrix of shared responsibilities. Maternal and Neonatal Health. 2001, 23-31.Google Scholar

6. Hiluf M, Fantahun M: Birth Preparedness and Complication Readiness among women in Adigrat town, north Ethiopia. Ethiop J Health Dev 2007, 22(1):14-20.

7. Federal democratic republic of Ethiopia ministry of health, basic emergency obstetric \& newborn care (BEMONC) training manual. A: Ministry of health, April 2010,1st Ed.

8. McPherson RA, Khadka N, Moore JM, Sharma M: Are birth-preparedness programmes effective? Results from a field trial in Siraha district, Nepal. Journal of Health Population and Nutrition. 2006, 24 (4): 479-88. Google Scholar.

9. Babalola S, Fatusi A: Determinants of use of maternal health services in Nigeria-looking beyond individual and household factors. BMC Pregnancy \& Childbirth. 2009, 9: 43-10.1186/1471-2393-9-43.View ArticleGoogle Scholar

10. United Nations. The sustainable development goals report 2016. 2016.Google Scholar

11. Katz DA, Kiarie JN, John-Stewart GC, et al. Male perspectives on incorporating men into antenatal HIV counseling and testing. PLoS One. 2009 Nov 2;4(11):e7602. doi: 10.1371/journal.pone.0007602.

12. Iliyasu Z, Abubakar IS, Galadanci HS, et al. Birth preparedness, complication readiness and fathers'

\section{Original Research Article}

participation in maternity care in a northern Nigerian community. Afr J Reprod Health. 2010 Mar;14(1):21-32.

13. Odimegwu C, Adewuyi A, Odebiyi T, et al. Men's role in emergency obstetric care in Osun State of Nigeria. Afr J Reprod Health. 2005 Dec; 9 (3):59-71.

14. Katz DA, Kiarie JN, John-Stewart GC, et al. Male perspectives on incorporating men into antenatal HIV counseling and testing. PLoS One. 2009 Nov 2;4 (11): e7602. doi: 10.1371/journal.pone.0007602.

15. Msuya SE, Mbizvo EM, Hussain A, et al. Low male partner participation in antenatal HIV counselling and testing in northern Tanzania: implications for preventive programs. AIDS Care. 2008 Jul;20(6):700-9. doi: 10. 1080/ 09540120701687059 .

16. Martin LT, McNamara MJ, Milot AS, Halle T, Hair EC: The effects Orne-Gliema involvement during pregnancy on receipt of prenatal care and maternal smoking. Maternal Child Health J. 2007, 11: 595-602. 10.1007/s10995-007-0209-0.View ArticlePubMedGoogle Scholar.

17. Orne-Gliemann J, Desgrées-Du-Loû A. The involvement of men within prenatal HIV counselling and testing. Facts, constraints and hopes. AIDS. 2008 Nov 30;22 (18):2555-7. doi: 10.1097/QAD.0b013e32831c54d5.

18. Onayade AA, Akanbi OO, Okunola HA, et al. Birth preparedness and emergency readiness plans of antenatal clinic attendees in Ile-ife, Nigeria. Niger Postgrad Med J. 2010 Mar;17(1):30-9.

19. Mutiso SM, Qureshi Z, Kinuthia J. Birth preparedness among antenatal clients. East Afr Med J. 2008 Jun;85 (6):275-83.

20. World Health Organization. WHO recommendations on health promotion interventions for maternal and newborn health 2015: World Health Organization; 2015. Google S

21. Biza A, Jille-Traas I, Colomar M, et al. Challenges and opportunities for implementing evidence-based antenatal care in Mozambique: a qualitative study. BMC Pregnancy Childbirth. 2015 Sep 2;15:200. doi: 10.1186/ s12884-015-0625-x.

22. August F, Pembe AB, Mpembeni R, Axemo P, Darj E. Men's knowledge of obstetric danger 23]signs, birth preparedness and complication readiness in rural Tanzania. PLoS One. 


\section{Original Research Article}

22. August F, Pembe AB, Mpembeni R, et al. Men's Knowledge of Obstetric Danger Signs, Birth Preparedness and Complication Readiness in Rural Tanzania. PLoS One. 2015 May 7;10 (5):e0125978. doi: 10.1371/journal. pone. 0125978 . eCollection 2015.

23. Kabakyenga JK, Östergren PO, Turyakira E, et al. Influence of birth preparedness, decision-making on location of birth and assistance by skilled birth attendants among women in south-western Uganda.PLoS One. 2012; 7(4): e35747. doi: 10.1371/journal.pone. 0035747. Epub 2012 Apr 27.

24. Wai KM, Shibanuma A, Oo NN, Fillman TJ, Saw YM, Jimba M. Are husbands involving in their spouses' utilization of maternal care services?: a cross-sectional study in Yangon, Myanmar. PLoS One. 2015; 10 (12): e0144135.View ArticlePubMedPubMedCentralGoogle Scholar.

25. Iliyasu Z, Abubakar IS, Galadanci HS, et al. Birth preparedness, complication readiness and fathers' participation in maternity care in a northern Nigerian community. Afr J Reprod Health. 2010 Mar;14(1):21-32.

26. Haftom Gebrehiwot Weldearegay. Determinant Factors of Male Involvement in Birth Preparedness and Complication Readiness at MekelleTown; a community Based Study. Science Journal of Public Health. Vol. 3, No. 2, 2015, pp. 175-180. doi: 10. 11648/j.sjph. 20150302.14 .

\section{How to cite this article?}

Mahendra G, Afra Farheen M.V, Vijayalakshmi. S. Husband's participation in birth preparedness and complication readiness. Obs Rev:J obstet Gynecol 2018;4(4):95-102.doi:10.17511/joog.2018.i04.05. 